\title{
Carbon nanostructures and graphite-coated metal nanostructures obtained by pyrolysis of ruthenocene and ruthenocene-ferrocene mixtures
}

\author{
L S PANCHAKARLA ${ }^{\dagger}$ and A GOVINDARAJ ${ }^{*}, \dagger$ \\ *Solid State and Structural Chemistry Unit, Indian Institute of Science, Bangalore 560 012, India \\ ${ }^{\dagger}$ CSIR Centre of Excellence in Chemistry, DST Unit on Nanoscience and Chemistry and Physics of Materials Unit, \\ Jawaharlal Nehru Centre for Advanced Scientific Research, Jakkur P.O., Bangalore 560 064, India
}

MS received 16 January 2007

\begin{abstract}
Pyrolysis of ruthenocene carried out in an atmosphere of argon or hydrogen is found to give rise to spherical nanoparticles of carbon with diameters in the 10-200 $\mathrm{nm}$ range. Pyrolysis of ruthenocene as well as mixtures of ruthenocene and ethylene in hydrogen gives rise to spherical nanoparticles, which contain a high proportion of $s p^{3}$ carbon. Under certain conditions, pyrolysis of ruthenocene gives rise to graphite coated ruthenium nanoparticles as well as worm-like carbon structures. Pyrolysis of mixtures of ruthenocene and ferrocene gives rise to nanoparticles or nanorods of FeRu alloys, the composition depending upon the composition of the original mixture. Nanorods of the Ru and FeRu alloys encapsulated in the carbon nanotubes are also formed in the pyrolysis reaction.
\end{abstract}

Keywords. Carbon nanotubes; nanoparticles; nanorods; pyrolysis; metallocene; FeRu alloy.

\section{Introduction}

Pyrolysis of organometallic precursors has been employed to prepare novel carbon structures by several workers (Andrews et al 1999; Huang et al 1999, 2000; Rao et al 2001; Govindaraj and Rao 2002). Thus, pyrolysis of metallocenes such as ferrocene, cobaltocene and nickelocene in the presence or absence of other hydrocarbons gives carbon nanotubes without any external metal catalyst (Rao et al 1998). Such pyrolysis also gives rise to metal particles such as Co and Fe covered by graphite sheets or carbon coated metal nanoparticles (Sen et al 1997). The nature of pyrolysis of hydrocarbons such as benzene in an inert atmosphere gives rise to fine uniform size spherical particles of carbon, which are established to be graphite type (Govindaraj et al 1997). Even though several studies have been carried out on the preparation of ruthenium particles decorated on carbon structures (Garcia et al 2006; Qiu et al 2006; Tsai et al 2006), there has been no systematic study on the pyrolysis of ruthenocene, $\mathrm{Ru}\left(\mathrm{C}_{5} \mathrm{H}_{5}\right)_{2}$, to generate carbon-supported metal structures. Like other metallocenes, ruthenocene also sublimes and by using an inert carrier gas one can transport and decompose this ruthenocene vapour at high temperatures. We have carried out the pyrolysis of ruthenocene to study the nature of nanoparticles obtained from the decomposition of ruthenocene. We also studied the

*Author for correspondence (govind@jncasr.ac.in) pyrolysis of ruthenocene with different carbon sources (hydrocarbons), different carrier gases and temperatures.

\section{Experimental}

The two procedures used for the pyrolysis of ruthenocene are as follows. In procedure 1 , typically $100 \mathrm{mg}$ of ruthenocene was taken in a stainless steel autoclave (Swagelok) of $20 \mathrm{ml}$ capacity and then sealed in an argon atmosphere. The autoclave was then placed inside a horizontal tube furnace maintained at $1000^{\circ} \mathrm{C}$ for $10 \mathrm{~min}$ (in an inert atmosphere) and then cooled to room temperature. After opening the autoclave the black pyrolyzed product was collected and analysed. This procedure is similar to that reported by Shanmugam and Gedanken (2006) for the preparation of carbon nanotubes by the pyrolysis of Ru(III) acetylacetonate. In procedure 2, Ru containing carbon materials were prepared by the pyrolysis of ruthenocene along with ethylene using a procedure similar to that for the synthesis of carbon nanotubes (Rao et al 1998). A known quantity of ruthenocene was placed in a quartz boat located at one end of a narrow quartz tube (10 $\mathrm{mm}$ inner diameter) which in turn was placed in a duel (two-stage) furnace system. The part of the quartz tube containing ruthenocene was in the first furnace and ruthenocene was sublimed by raising the temperature to $400^{\circ} \mathrm{C}$ at a heating rate of $50^{\circ} \mathrm{C} / \mathrm{min}$. Argon (hydrogen in the case of synthesis of elongated particles) was used as a carrier gas for carrying the ruthenocene vapours into the second furnace. The role of ethylene was 
to provide an additional carbon source. Ethylene was admitted into the reaction tube just before the sublimation of ruthenocene. The flow rates of the gases were controlled using the UNIT mass flow controllers. Pyrolysis takes place inside the second furnace and its temperature was maintained constant for each reaction and was varied from $900-1300^{\circ} \mathrm{C}$ (from one reaction to other). Pyrolysis yielded profuse quantities of carbon deposits at the centre and outlet of the second furnace. The samples collected from the interior of the quartz reaction tube gives elongated carbon spheres, carbon coated metal particles and worm-shaped carbon structures. Similar experiments were carried out to prepare $\mathrm{FeRu}$ metal alloy nanorods inside the carbon nanotubes (CNTs). In this case, we used $1: 1,1: 4$ and $4: 1$ (molar ratios) of ruthenocene-ferrocene mixtures for pyrolysis.

Scanning electron microscopic (SEM) images of the samples were recorded using a LEICA S440i scanning electron microscope. Field emission scanning electron microscopic (FESEM) images were recorded with a FEI NOVA NANOSEM 600. XRD patterns of the samples were recorded in the $\theta-2 \theta$ Bragg-Bretano geometry with a Siemens D5005 diffractometer using $\operatorname{CuK}_{\alpha}(\lambda=0 \cdot 151418 \mathrm{~nm})$ radiation. Raman spectra were recorded with LabRAM HR high resolution Raman microscope (Horiba Jobin Yvon) using $\mathrm{He}-\mathrm{Ne}$ laser $(\lambda=630 \mathrm{~nm})$. TEM images were recorded using transmission electron microscopes (TEM) JEOL JEM 3010 and FEI Tecnai S30 operating at $300 \mathrm{kV}$. Magnetic measurements were carried out for different samples by using the vibrating sample magnetometer (VSM) in PPMS (Physical Property Measurement System).

\section{Results and discussion}

A SEM image of the carbon spheres obtained by the pyrolysis of ruthenocene in an $\mathrm{Ar}$ atmosphere at $1000^{\circ} \mathrm{C}$, using procedure 1 , is shown in figure 1a. These unconnected spheres are graphitic, having diameters ranging from $500 \mathrm{~nm}-$ $1 \mu \mathrm{m}$. Carbon spheres of uniform size were also obtained by the pyrolysis of ruthenocene in the presence or absence of hydrocarbons using procedure 2. Figure $1 \mathrm{~b}$ shows a SEM image of uniform-sized carbon spheres of $~ 300 \mathrm{~nm}$ diameter obtained in the presence of $200 \mathrm{sccm}(\mathrm{sccm}=$ standard cubic centimeter per minute) of argon carrier gas at $1300^{\circ} \mathrm{C}$. Reactions carried out using procedure 2 at different temperatures in the $1000-1300^{\circ} \mathrm{C}$ range, under similar conditions yielded similar carbon spheres of uniform size. However, pyrolysis of the ruthenocene-ethylene mixture at $1350^{\circ} \mathrm{C}$ (with hydrogen and ethylene flow rates of 150 and $50 \mathrm{sccm}$, respectively) gives connected carbon spheres of around $70 \mathrm{~nm}$ diameter, as shown in the FESEM image of figure 1c. Interestingly, these carbon spheres are different from the spheres obtained in the absence of the hydrocarbon (shown in figures 1a and $b$ ). The Raman spectrum of these carbon spheres is shown in figure $2 \mathrm{a}$. We observe intense
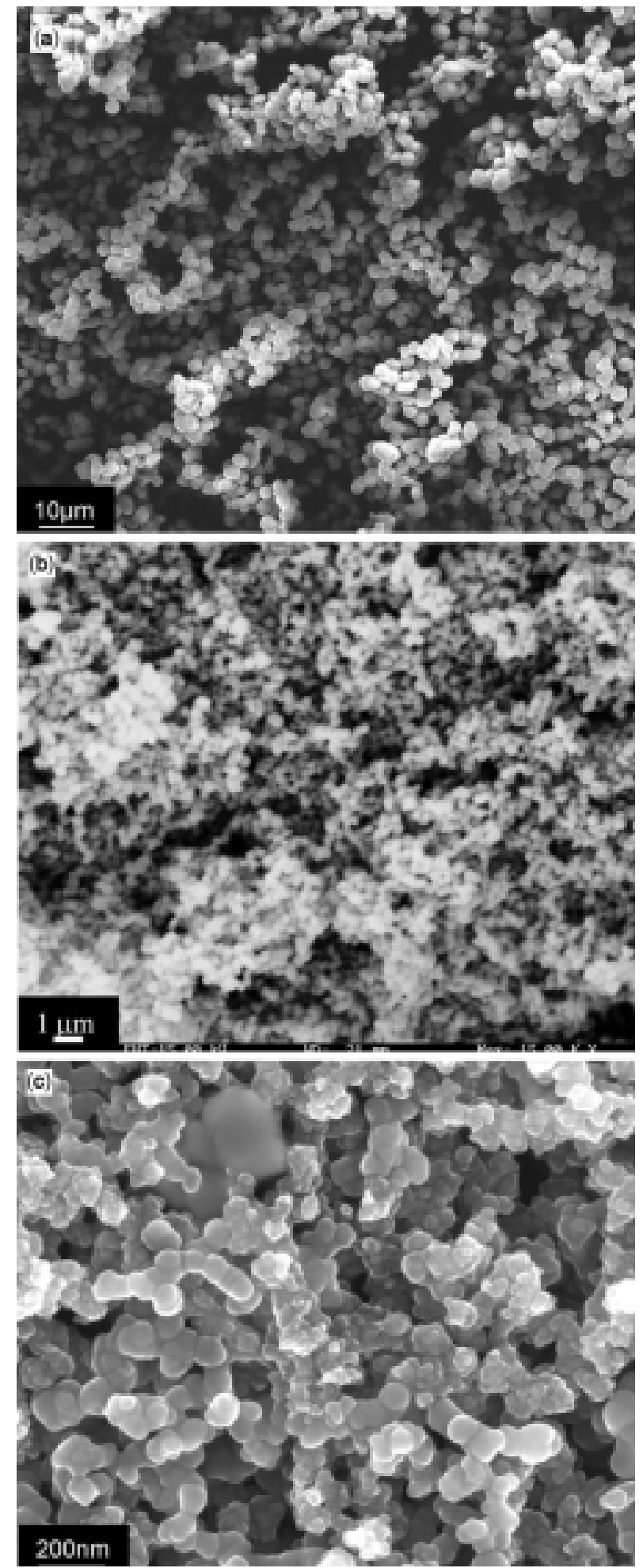

Figure 1. (a) SEM images of ruthenium supported carbon spheres prepared by pyrolysis of ruthenocene at $1000^{\circ} \mathrm{C}$ in argon atmosphere using procedure 1, (b) SEM images of ruthenium supported carbon spheres prepared by pyrolysis of ruthenocene at $1300^{\circ} \mathrm{C}$ in the presence of argon, $200 \mathrm{sccm}$, by using procedure 2 and (c) FESEM images of ruthenium supported carbon spheres prepared by pyrolysis of ruthenocene at $1350^{\circ} \mathrm{C}$ in the presence of hydrogen and ethylene flow rates of 150 and $50 \mathrm{sccm}$, respectively, by using procedure 2 . 

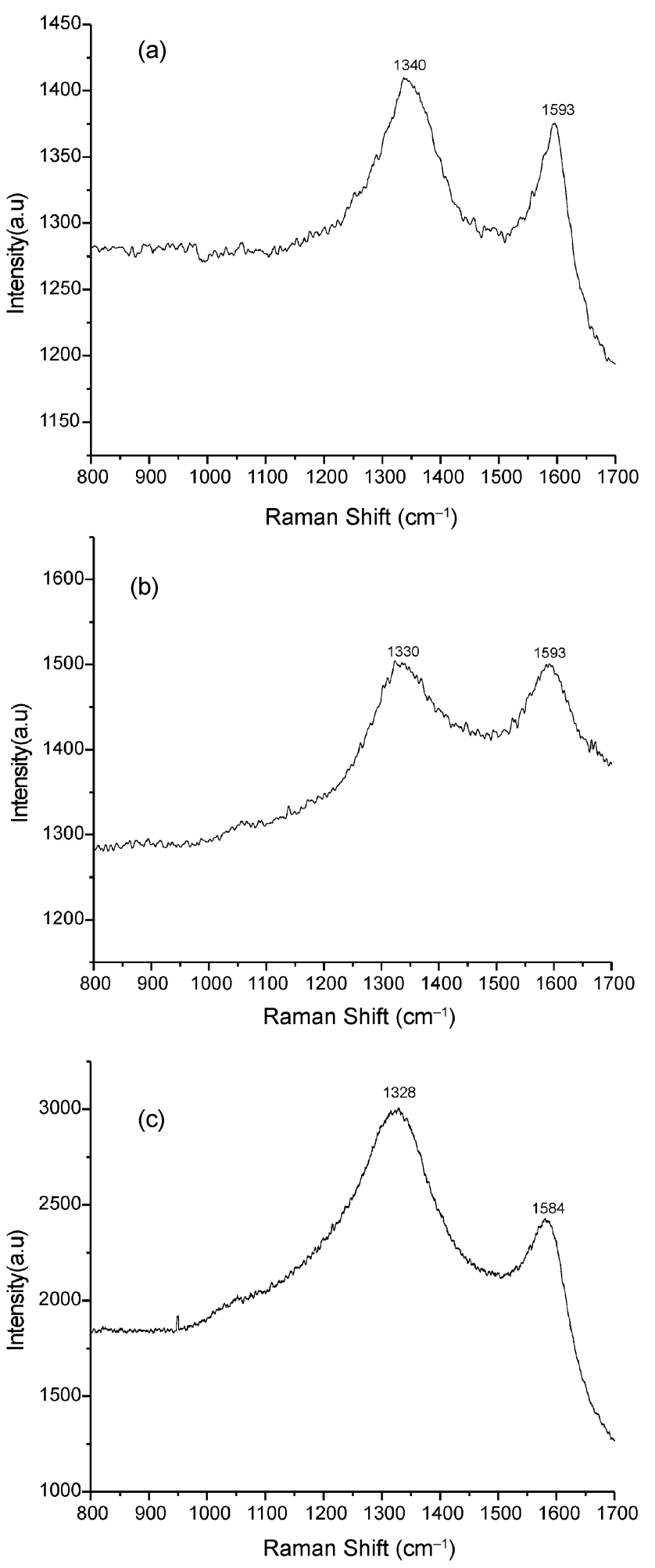

Figure 2. Raman spectra of Ru-supported carbon spheres prepared under different conditions: (a) by pyrolysis of ruthenocene at $1350^{\circ} \mathrm{C}$ in a mixture of hydrogen and ethylene gases with flow rates of 150 and $50 \mathrm{sccm}$, respectively, (b) by pyrolysis of ruthenocene in argon and ethylene mixture with flow rates of 150 and $50 \mathrm{sccm}$, respectively at $1100^{\circ} \mathrm{C}$ and (c) pyrolysis of ruthenocene in argon $(150 \mathrm{sccm})$ with a mixture of $50 \mathrm{sccm}$ of ethylene bubbled through thiophene at $950^{\circ} \mathrm{C}$. bands at 1340 and $1593 \mathrm{~cm}^{-1}$, the former being due to $s p^{3}$ carbon as in diamond and the latter due to graphitic $\left(s p^{2}\right)$ carbon. The relative intensities of these two bands indicate the dominance of $s p^{3}$ carbon over $s p^{2}$ carbon and the material looks almost pure glassy carbon or diamond-like carbon.

Pyrolysis of ruthenocene with a mixture of argon and ethylene with flow rates of 150 and $50 \mathrm{sccm}$, respectively at $1100^{\circ} \mathrm{C}$ gives carbon spheres with diameters in the
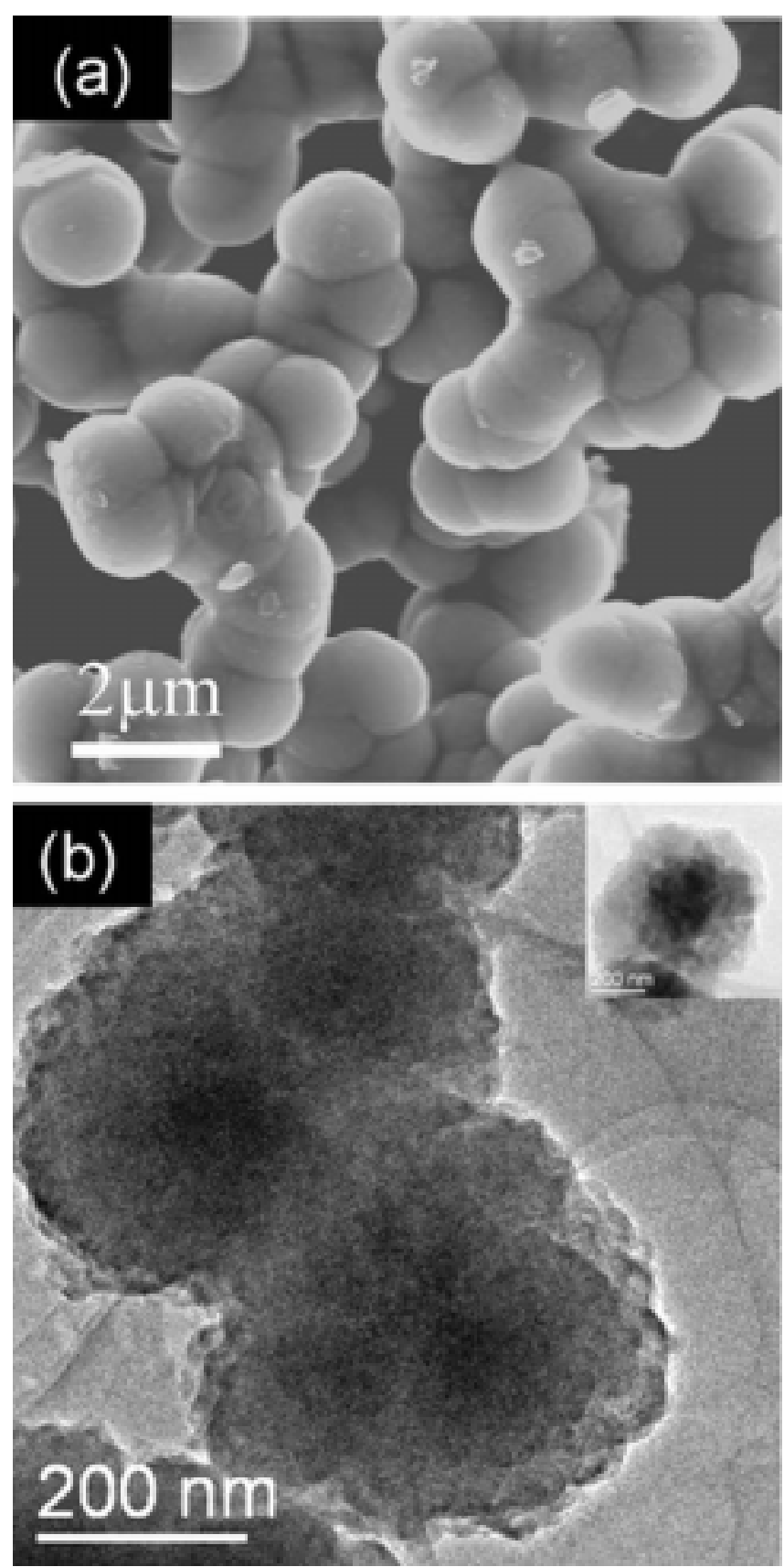

Figure 3. (a) FESEM images of carbon spheres prepared by pyrolysis of ruthenocene at $1100^{\circ} \mathrm{C}$ in the presence of argon and ethylene with flow rates of $150,50 \mathrm{sccm}$, respectively and (b) shows a TEM image of the spheres, the inset showing a single sphere of carbon coated ruthenium. 
500-800 $\mathrm{nm}$ range, as shown in figure 3a. The Raman spectrum of these spheres is shown in figure $2 b$ which shows bands at 1330 and $1593 \mathrm{~cm}^{-1}$ of similar intensities, indicating the presence of equal amount of $s p^{2}$ and $s p^{3}$ carbon. In figure $3 b$, we show a TEM image of amorphous carbon-coated ruthenium nanoparticle. EDAX analysis shows the presence of ruthenium. The inset in figure $3 b$ shows a TEM image of a carbon-coated Ru particle. The electron diffraction pattern as well as the XRD pattern (see figure $4 \mathrm{a}$ ) of these nanospheres confirm the HCP structure of $\mathrm{Ru}(a=2.698 \AA$ and $c=4.272 \AA$, JCPDS file: 021258).

Worm-like carbon structures were obtained by the pyrolysis of ruthenocene at $950^{\circ} \mathrm{C}$ in the presence of thiophene, argon and ethylene at flow rates of $150 \mathrm{sccm}$ and $50 \mathrm{sccm}$, respectively, in these experiments, ethylene was bubbled through thiophene throughout the reaction. SEM and TEM images of the worm-like carbon structures are shown in figures $5 \mathrm{a}$ and $\mathrm{b}$, respectively. The elongated structures have a diameter of around $1 \mu \mathrm{m}$. EDAX analysis shows the presence of $\mathrm{Ru}$. The Raman spectrum of these carbon structures (figure 2c) shows that $s p^{3}$ carbon is in majority rather than $s p^{2}$ carbon.

By using ferrocene instead of ruthenocene, under the conditions of procedure 2 , we obtained carbon nanotubes rather than carbon spheres as in the case of ruthenocene (Rao et al 1998, 2001; Govindaraj and Rao 2002). This may be due to the higher stability, diffusion as well as the solubility of carbon in $\mathrm{Fe}$ with a lower eutectic temperature. The $\mathrm{Fe}-\mathrm{C}$ phase diagram shows a maximum solubility of carbon in $\mathrm{Fe}$ to be around 7\%. The eutectoid composition is $\mathrm{Fe}-0.83 \mathrm{wt} \% \mathrm{C}$ and at this composition the high-temperature

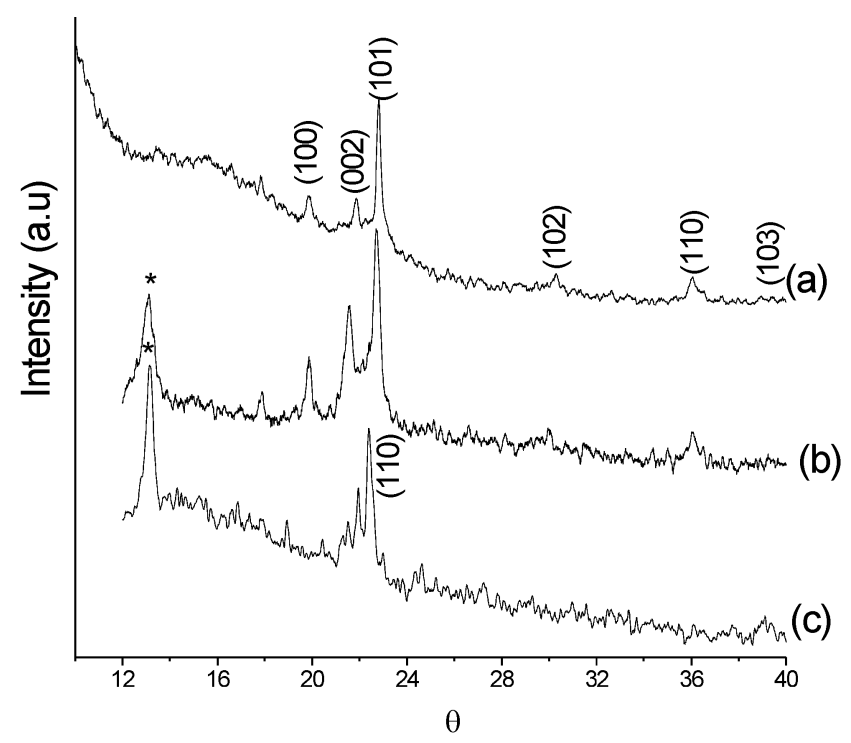

Figure 4. XRD patterns of (a) ruthenium supported carbon spheres, (b) FeRu $(1: 1)$ binary alloy nanowires inside carbon nanotubes and (c) iron nanowires encapsulated inside carbon nanotubes (asterisk corresponds to carbon nanotube peak). austenite phase will undergo eutectoid reaction at $723^{\circ} \mathrm{C}$ and at this temperature $\gamma$-Fe, $\alpha$-Fe and carbon or $\left(\mathrm{Fe}_{3} \mathrm{C}\right)$ may coexist (Kim and Sigmund 2005). Also, the $\mathrm{Ru}-\mathrm{C}$ phase diagram is a simple eutectic with a eutectic temperature of $1940^{\circ} \mathrm{C}$ and eutectic concentration of $\sim 18$ at. $\% \mathrm{C}$ and maximum solubility of $\mathrm{C}$ being $\sim 0.37$ wt.\% C. Since RuC is unstable with decreasing temperature, carbon precipitates in the form of graphite on the basal planes. Although $\mathrm{Ru}$ does not form carbides at room temperature, soluble carbon
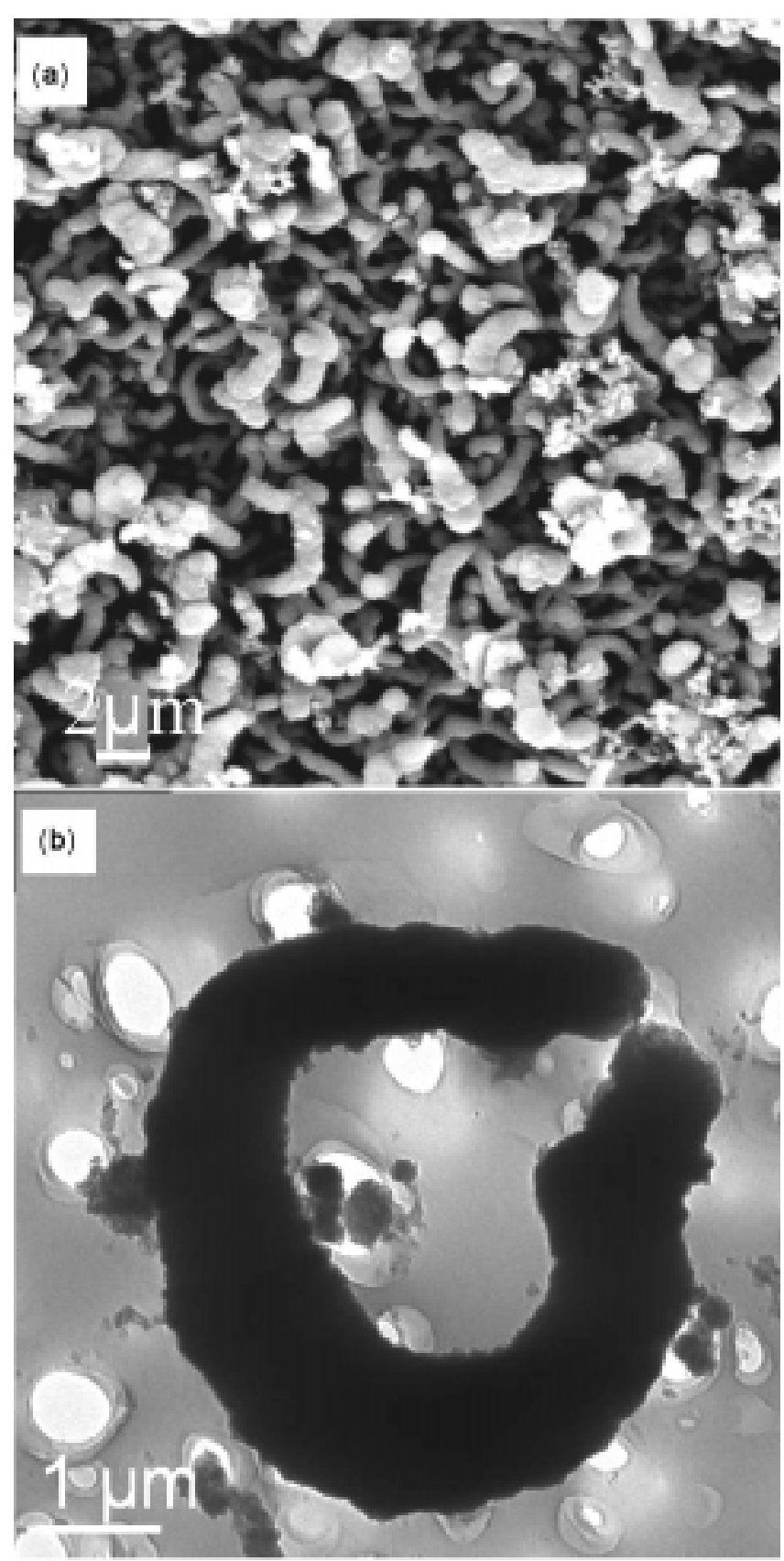

Figure 5. (a) SEM image of carbon structures prepared by pyrolysis of ruthenocene with a mixture of argon $(150 \mathrm{sccm})$ and ethylene $(50 \mathrm{sccm})$ bubbled through thiophene at $950^{\circ} \mathrm{C}$ and (b) shows the TEM image of these structures. 

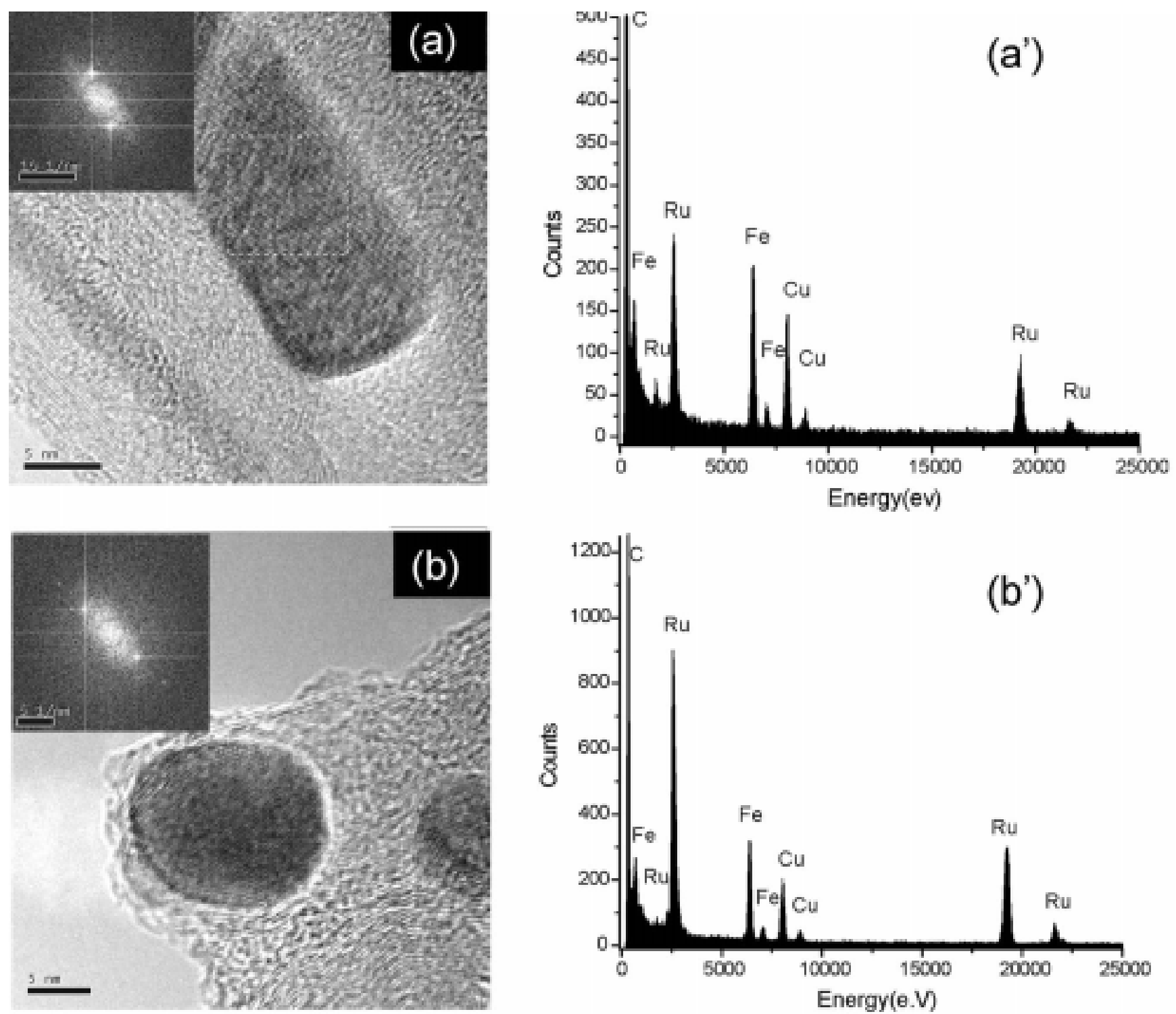

Figure 6. The high magnification TEM images of FeRu alloy nanoparticles and nanorods (inside the carbon nanotubes) obtained by the pyrolysis of a mixture of ruthenocene and ferrocene $(1: 1)$ in the presence of Ar and ethylene $(500$ and $50 \mathrm{sccm}$, respecti-

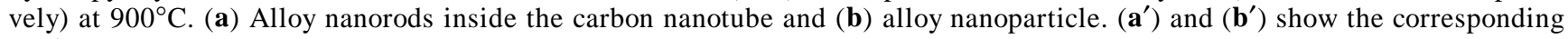
EDAX patterns.

$(\sim 0.04$ wt. $\% \mathrm{C}$ at room temperature) strongly affects hardness and resistivity, and impairs workability (Savitskii et al 1973). Thus, the $\mathrm{Fe}-\mathrm{C}$ phase diagram seems to indicate the formation of Fe catalysed growth of carbon nanotubes. Since ruthenium itself is not incorporated and forming carbon nanotubes, we thought it interesting to see the effect of addition of ruthenocene to ferrocene on the growth of carbon nanotubes. It was also of interest to see whether Ru particles decorate the carbon nanotube surface or get encapsulated inside the nanotubes. Interestingly, we found bimetallic FeRu nanostructures which get encapsulated inside the nanotubes as seen in figures 6 and 7 .

We were able to get $\mathrm{FeRu}$ alloy nanorods inside the carbon nanotubes as well as carbon-coated FeRu alloy nanoparticles by the pyrolysis of a mixture of ruthenocene and ferrocene of different molar ratios $(1: 1,1: 4,4: 1)$ in the presence of argon and ethylene (500 and $50 \mathrm{sccm}$, respectively) at $900^{\circ} \mathrm{C}$. Due to relatively high temperature involved in the synthesis, we are expected to obtain the HCP structure for all the above compositions of FeRu alloy nanostructures (Moon et al 2000). The 1:4 FeRu alloy nanostructure has lattice constants, $a=2 \cdot 70 \AA$ and $c=$ $4 \cdot 27 \AA$ (JCPDS file: 40-1147) and the $1: 1$ FeRu alloy nanostructure has lattice constants, $a=2.60 \AA$ and $c=4 \cdot 17 \AA$. A systematic decrease in the $d$-spacing was also observed in all $\mathrm{FeRu}$ alloy nanostructures as compared to pure $\mathrm{Ru}$, confirming that the smaller Fe atoms are indeed incorporated in the larger Ru lattice. Figure 6a shows a typical high 
resolution TEM image of the $1: 1$ alloy nanorod showing a $d$-spacing of $2 \cdot 1 \AA$. Figure 6 b shows a high resolution TEM image of $1: 4$ FeRu alloy nanoparticle showing a $d$ spacing of $2.4 \AA$, confirming the single-crystalline nature. From EDAX analysis (figure 6), the $\mathrm{Ru}$ : Fe ratio was found to be $1: 1$ in the case of nanorods formed inside the CNTs and 4:1 in the case of encapsulated nanoparticles. The electron diffraction patterns shown as insets in figures $6 \mathrm{a}$ and $\mathrm{b}$ correspond to the alloys and indicate the nanostructures to be single crystalline. The carbon coating in the FeRu nanoparticles is graphitic as can be seen from the TEM image. Figures $7 \mathrm{a}$ and $\mathrm{b}$ show low magnification TEM images of metal alloy $(1: 1)$ nanorods formed inside CNTs.

Magnetic measurements were carried out on different carbon nanostructures prepared by the pyrolysis of ferro-

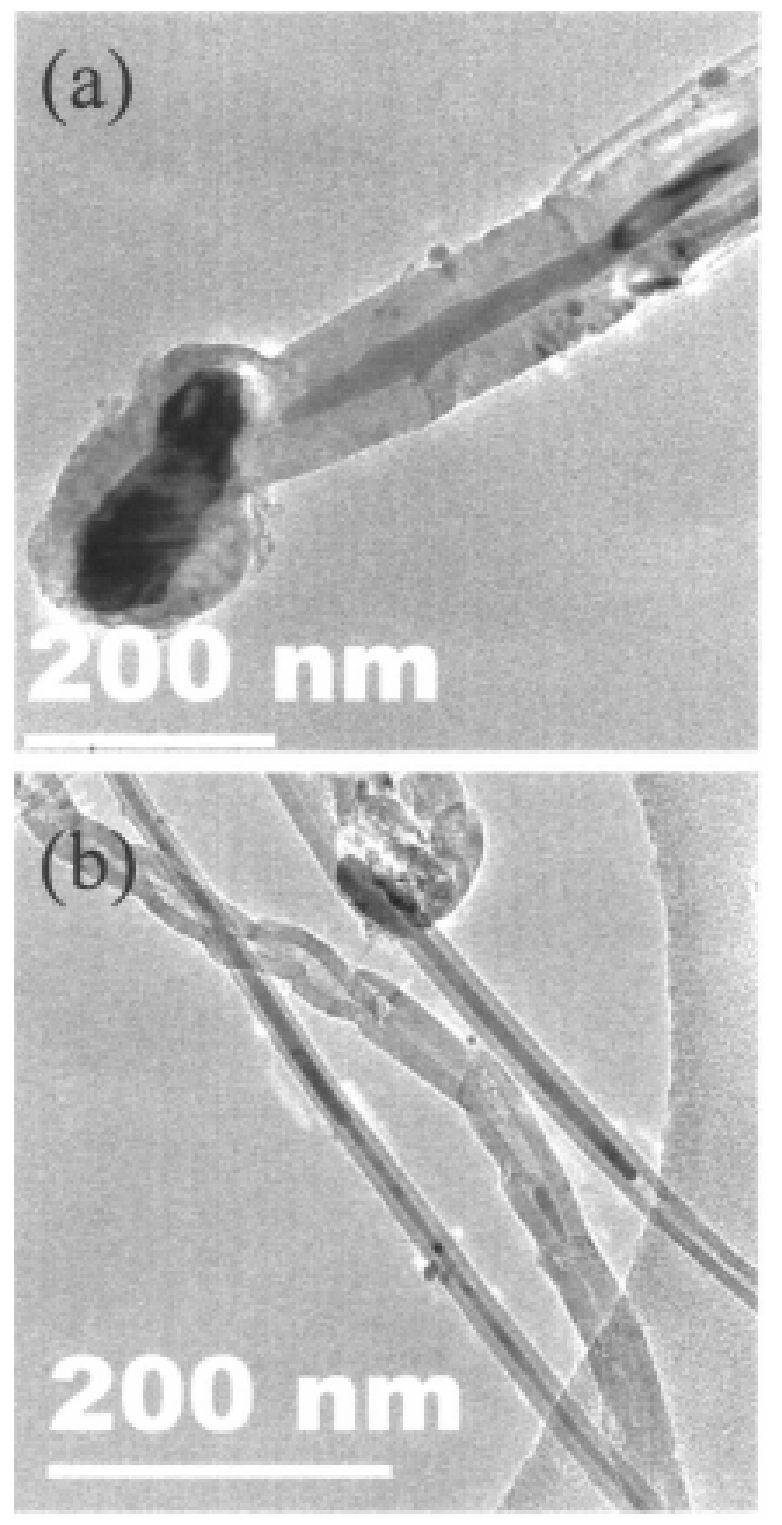

Figure 7. (a)-(b) Low magnification TEM images of ironruthenium alloy nanorods inside carbon nanotubes. cene, ferrocene-ruthenocene mixtures and ruthenocene in the presence as well as in the absence of hydrocarbons. Magnetic measurements on aligned carbon nanotubes obtained from the pyrolysis of ferrocene-hydrocarbon mixtures have been reported earlier, wherein the $M$ vs $H$ curves showed a smooth S-shaped loop with a saturation magnetization of $\sim 24 \mathrm{emu} / \mathrm{g}$ which is smaller than that of bulk iron (Satishkumar et al 2002). In the present measure-

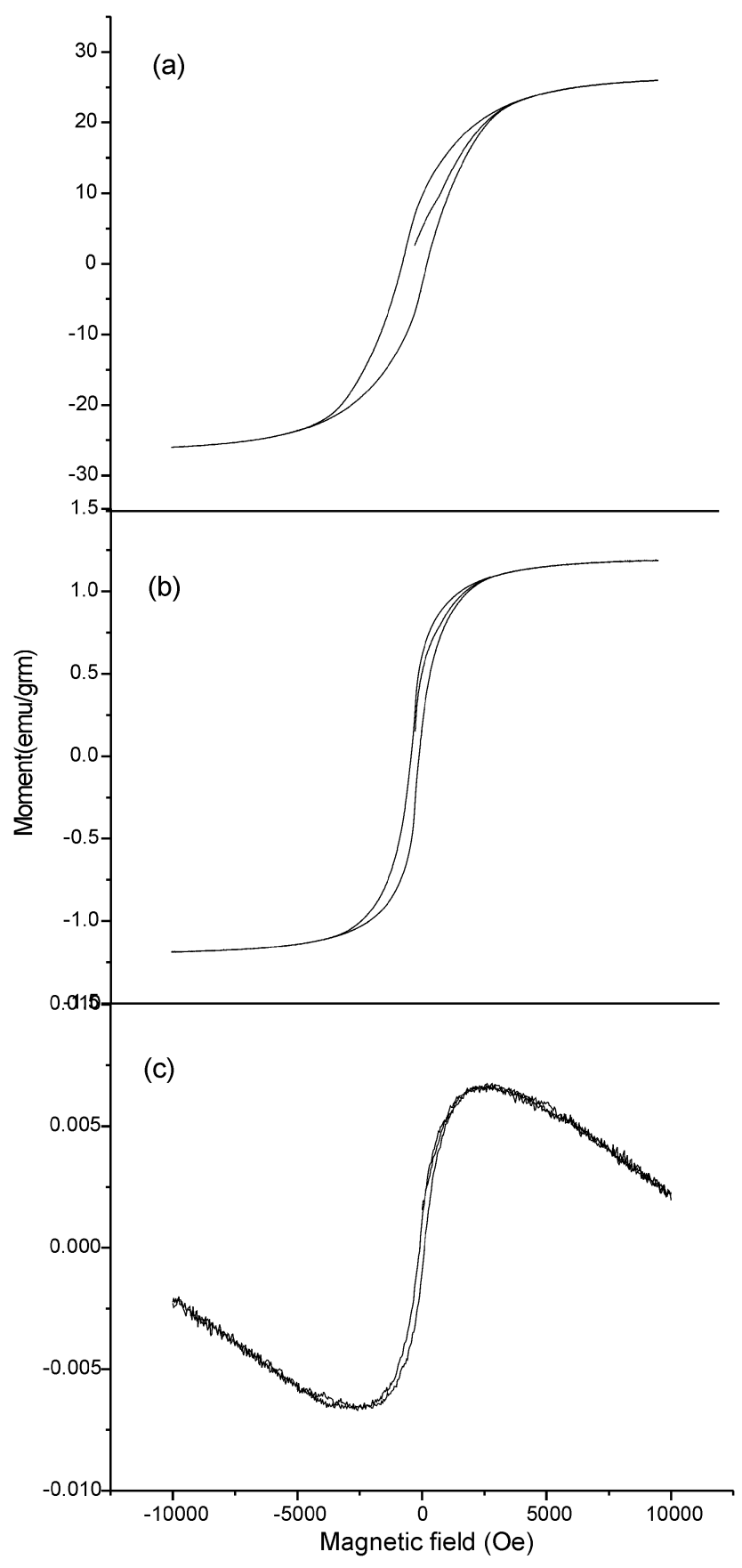

Figure 8. Hysteresis loops ( $M$ vs $H$ curves) recorded on samples: (a) iron nanowires encapsulated inside carbon nanotubes, (b) FeRu (1:1) binary alloy nanowires inside carbon nanotubes and (c) carbon coated Ru nanoparticles. 
ments, a maximum field of $\sim 1 \mathrm{~T}$ was applied from the start, swept through zero field, and the direction of the field reversed to get $M$ vs $H$ hysteresis loops. Figure 8 shows typical hysteresis ( $M$ vs $H$ ) curves. It is observed that the saturation magnetization decreases from pure iron nanowire encapsulated in carbon nanotubes (prepared by ferrocene pyrolysis) to carbon coated/encapsulated binary FeRu (4:1, 1:4, 1:1) alloy nanostructures (prepared by ferrocene-ruthenocene pyrolysis) and to carbon-coated $\mathrm{Ru}$ particles (prepared by ruthenocene pyrolysis), respectively. The saturation magnetization $\left(M_{\mathrm{s}}\right)$ of $26,7,1.2,10 \cdot 7$, $0.007 \mathrm{emu} / \mathrm{g}$ was recorded for the samples such as iron nanowires encapsulated inside carbon nanotubes, FeRu $(4: 1,1: 1,1: 4)$ binary alloy nanowires inside carbon nanotubes and carbon coated $\mathrm{Ru}$ nanoparticles, respectively while the corresponding coercivity $\left(H_{\mathrm{c}}\right)$ was 507, 205, 157, 194, and 20 Oe. In the case of carbon coated Ru nanoparticles, we have observed very low magnetization. Bulk Ru is nonmagnetic whereas in nanosize domains it shows ferromagnetism. Recently, universal ferromagnetism has been found in nanoparticles (Sundaresan et al 2006). In nanosize particles, surface magnetism dominates at low fields and shows hysteresis. At high fields, diamagnetism dominates. It is also known that magnetic elements such as $\mathrm{Fe}, \mathrm{Co}$ and $\mathrm{Ni}$ in nanoscale show enhanced moments due to the reduced coordination of atoms and localization of electrons as compared to the case of bulk materials (Billas et al 1994). The spin and orbital contribution to surface magnetism in the $3 d$ elements have been reported (Eriksson et al 1992). Several groups have studied magnetism of $4 d$ element nanoclusters and thin films (Moruzzi and Marcus 1990; Cox et al 1994; Piveteau et al 1996; García et al 1999; Cabria et al 2002; Bae et al 2004; Wang et al 2006). Hence, most of the studies point out that magnetism in nanoregime is a surface phenomena.

\section{Conclusions}

Unlike the pyrolysis of ferrocene, cobaltocene and nickelocene where carbon nanotubes are readily obtained, pyrolysis of ruthenocene mainly gives rise to carbon nanospheres. Under certain conditions, carbon coated Ru nanoparticles were also obtained. Mixtures of ruthenocene with ferrocene also gives rise to FeRu metal nanoparticles and also nanorods covered by carbon, the latter being encapsulated inside carbon nanotubes. The pyrolysis method gives rise to useful means to produce nanoparticles of $\mathrm{Ru}$ and FeRu alloys. It may be noted that carbon spheres themselves can be obtained by the pyrolysis of hydrocarbon (Govindaraj et al 1997). In view of this, it appears as though during the pyrolysis of ruthenocene, cyclopentadienyl radicals undergo decomposition just as in the case of decomposition of pure benzene giving rise to pure carbon structures, with ruthenium particles forming separate nanoparticles. In the case of $\mathrm{Fe}, \mathrm{Co}$ and $\mathrm{Ni}$, they appear to be better catalysts than $\mathrm{Ru}$ to form nanotubes.

\section{Acknowledgements}

The authors thank Prof. C N R Rao for suggesting this problem, encouragement and guidance. We also thank Dr A Sundaresan for magnetic measurements. One of the authors (LSP) acknowledges CSIR, New Delhi, for a junior research fellowship.

\section{References}

Andrews R, Jacques D, Rao A M, Derbyshire F, Qian D, Fan X, Dickey E C and Chen J 1999 Chem. Phys. Lett. 303467

Bae Y C, Osanai H, Kumar V and Kawazoe Y 2004 Phys. Rev. B70 195413

Billas I M L, Chatelain A and de Heer W A 1994 Science 265 1682

Cabria I, Nonas B, Zeller R and Dederichs P H 2002 Phys. Rev. B65 054414

Cox A J, Louderback J G, Apsel S E and Bloomfield L A 1994 Phys. Rev. B49 12295

Eriksson O, Boring A M, Albers R C, Fernando G W and Cooper B R 1992 Phys. Rev. B45 2868

García A E, González-Robles V and Baquero R 1999 Phys. Rev. B59 9392

Garcia J, Gomes H T, Serp Ph, Kalck Ph, Figueiredo J L and Faria J L 2006 Carbon 442384

Govindaraj A and Rao C N R 2002 Pure Appl. Chem. 741571

Govindaraj A, Sen R, Raju B V N and Rao C N R 1997 Philos. Mag. Lett. 76363

Huang S, Dai L and Mau A W H 1999 J. Phys. Chem. B103 4223

Huang S, Mau A W H, Turney T W, White P A and Dai L 2000 J. Phys. Chem. B104 2193

Kim H and Sigmund W 2005 Carbon 431743

Moon H -J, Kim W, Oh S J, Park J, Park J -G, Cho E -J, Lee J I and Ri H -C 2000 J. Kor. Phys. Soc. 3649

Moruzzi V L and Marcus P M 1990 Phys. Rev. B42 10322

Piveteau B, Desjonqueres M -C, Andrzej, Oles M and Spanjaard D 1996 Phys. Rev. B53 9251

Qiu J, Zhang H, Wang X, Han H, Liang C and Li C 2006 Reaction Kinetics and Catalysis Lett. 88269

Rao C N R, Govindaraj A, Sen R and Satishkumar B C 1998 Mater. Res. Innovat. 2128

Rao C N R, Satishkumar B C, Govindaraj A and Nath M 2001 Chem. Phys. Chem. 278 and references therein

Satishkumar B C, Govindaraj A, Vanitha P V, Raychaudhuri A K and Rao C N R 2002 Chem. Phys. Lett. 362301

Savitskii E M, Polyakova V P and Gorina N B 1973 Vyrashchivanie Monokrist. Tugoplavkikh Redk. Metal, Conference Proceedings (Moscow (USSR): Nauka) p. 90 (in Russian)

Sen R, Govindaraj A and Rao C N R 1997 Chem. Phys. Lett. 267 276

Shanmugam S and Gedanken A 2006 J. Phys. Chem. B110 2037

Sundaresan A, Bhargavi R, Rangarajan N, Siddesh U and Rao C N R 2006 Phys. Rev. B74 161306(R)

Tsai M -C, Yeh T -K and Tsai C -H 2006 Electrochem. Commun. 81445

Wang W C, Kong Y, He X and Liu B X 2006 Appl. Phys. Lett. 89262511 